\title{
Study of the Learning Climate and the Feedback That Students Draw in the Mathematics Class
}

\author{
Ravanos Anastasios \\ Hellenic Open University, Patras, Greece \\ Email:std13458@ac.eap.gr
}

How to cite this paper: Anastasios, R. (2020) Study of the Learning Climate and the Feedback That Students Draw in the Mathematics Class. Open Access Library Journal, 7: e7029.

https://doi.org/10.4236/oalib.1107029

Received: November 23, 2020

Accepted: December 28, 2020

Published: December 31, 2020

Copyright $\odot 2020$ by author(s) and Open Access Library Inc.

This work is licensed under the Creative Commons Attribution International License (CC BY 4.0).

http://creativecommons.org/licenses/by/4.0/

\begin{abstract}
This study is the result of the completion of my dissertation, for the needs of which, in parallel with the literature review, a quantitative research was conducted to assess the learning climate and feedback in the classroom of mathematics as perceived by 50 students who participated. The purpose of the research is to highlight relevant issues and findings, as well as to be a trigger for other research efforts aimed at improving the teaching of Mathematics.
\end{abstract}

\section{Subject Areas}

Education

Keywords

Learning Climate, Feedback, Mathematics Class

\section{Introduction}

The self-knowledge of each student about the subject of mathematics has been formed by his involvement in the previous period with this subject and by a set of reviews, comments and evaluations. Proportional to the degree of self-esteem is their attitude towards the lesson. Considering that the math lesson for most students is considered to be aimed only at gifted students, we can easily conclude that math class is a boring time for others, also useless or at worst an hour of complete inactivity. In other cases, there is a phenomenon that even the "good" students abstain, especially when the teacher lowers the level of difficulty in trying to activate other students. In any case, the mathematician can intervene drastically and shape the appropriate learning climate in the classroom by involving all students in the educational process and the desired goal of improving their performance. In this endeavor, he always has a permanent partner in the 
feedback during which he gathers information and evaluates the student at every moment, but at the same time to provide him with the stimuli for greater participation, for deepening and more research. Previous meta-analytic studies showed that the interventions included Corrective Feedback are moderately effective [1].

\section{Theoretical Framework}

\subsection{Learning Climate in the Mathematics Classroom}

The learning climate in the mathematics classroom is the atmosphere that results from the teaching techniques used by the teacher and from the behavior and interaction of the teacher and students in order to develop students' knowledge in mathematics. According to Pirie and Schwarzenberger [2], the classroom climate can be defined as the interest shown by students during the Mathematics lesson and generally the conditions in which the Mathematics lesson is conducted.

The Learning climate in the classroom of mathematics is a sub-state of the Learning climate in the classroom of all subjects and this in turn is part of the wider pedagogical climate of a school. Of course, there may be a few exceptions. For example, in a school that is not so productive and efficient, there can be a mathematician whose climate in each of his classrooms is excellent. Conversely, in a well - functioning school to have a colleague of Mathematics, with the atmosphere in the classroom is such that it prevents students from any creative activity. If we accept that all colleagues in all specialties of the public school want the cognitive development of students, this will result from the creation of the best possible learning climate in each classroom. This depends on many factors, even external (indirect) factors related to the general education policy, the origin, the individuality of each child and the attitude of the family. But it mainly depends on intra-school factors, mainly the principal and the goals and visions he has, the well-informed and trained teachers, the cooperation between them and the cooperation of teachers with students and parents.

If we limit ourselves to the classroom, the formation of a suitable atmosphere in it by the mathematics teacher can be done in many ways.

First of all, like any teacher of any specialty, he must create such an atmosphere that every child feels safe, feels accepted and respected by the teacher and the other students, encouraged to cooperate, ask questions and have free participation in class. In addition, for the learning climate in the mathematics classroom, the application of appropriate learning strategies designed to engage students can be enriched by examples of nature and life as well as new technologies and software that simulate problems and project multiple representations.

Many factors determine the effectiveness of a teacher in the classroom, with the necessary condition of course the teaching experience and the perfect scientific training for the management and knowledge of the material and the curriculum. First of all, he takes care of the creation of a suitable pedagogical and 
learning climate in whatever class he is called to teach. In other words, it has the sole responsibility for the communication and behavior relations with each student, but also between the students (such as competition, episodes of disorder and disorder, etc.). The teacher should enthusiastically set clear goals, adaptable to the circumstances, and state them at various stages during the lesson.

The teaching of the teacher must have a proper organization of time and structure (i.e. it must contain a reference to the objectives, a brief presentation, a connection with the previous and the next and of course a summary). Where possible the teacher mentions examples and any applications of new knowledge in the real world. Throughout the lesson the teacher evaluates objectively by asking short and clear questions that can be answered, depending on his level, by each student, encouraging him and giving him each time the required time. If the answer is correct the student is praised and explanations are given for the correctness of the answer. If the answer is wrong or partially wrong, then the teacher should rephrase the question, but not to the point where the answer is obvious or monologue (yes or no). The teacher must be present whenever a student is looking for him. Over time, his interventions should be reduced, a sign that students have been taught and adopted methods of strategic approach and solving exercises and problems.

\subsection{Factors That Shape the Learning Climate}

One of the main factors that shape the learning climate in the mathematics classroom is the pedagogical climate of the classroom, i.e. the direct approach by the students to the whole educational process.

An equally important factor is the role of the teacher. The teacher's view of mathematics and how it should be taught greatly influences students' attitudes and performance. Due to the nature of the course, the mathematics teacher must know and use its use in approaching and solving everyday problems in life. Must be methodical and systematic especially when he has to introduce a new definition or a methodology for solving exercises and give all the necessary clarifications so that it can be understood.

Perhaps the most important factor is the attitude of the students themselves towards mathematics, because it is proportional to their performance in the lesson. Their attitude is determined by the students' view of mathematics and its usefulness in everyday life, as well as by the emotions they feel when practicing mathematics (joy or frustration, courage or fear).

Other factors that influence the Learning climate in the subject of Mathematics are the educational background of the parents and their attitude towards Mathematics. Since the teacher bears the greatest responsibility for the students' progress in mathematics, it is good to pay attention to the following:

1) Mathematics is a positive but also an abstract science. So the math teacher must be specific in the way he teaches. He makes sure that his students, with great dedication, are concentrated to finish a task or to understand new concepts. According to Cheung [3] the methodology of the mathematics teacher is 
considered as one of the most important factors on which the performance of students in a particular subject depends. In addition to the exercises with clear pronunciation about what he is asking for, there are also exercises with enough data and relationships, where the student needs to have enough experience to be able to choose what to use first and what to do next. At this point the relatively quick intervention of the teacher is needed in order to save time, but mainly so that the students do not start to feel the feeling of failure. Students should then be given more freedom.

2) Mathematics is a subject that requires speed of thought. Therefore, the teacher's reflexes must be fast, so that the student understands his mistake in time or to make sure of his doubts and return to the normality of the lesson. Also mathematics is a subject that the previous section is very much related to the next. The mathematician makes sure that there are no gaps, because the difficulties and the frustration work in multiplication.

3) There are many opportunities given to the math to "shut up" sometimes during the lesson. Let the students work on their own under his supervision and then give them the opportunity to interact, promoting constructive dialogue, without of course feeling that they are competing with each other.

4) The educational mathematician in the classroom should know that each student is a separate personality, has his own goals and rhythms. In some areas it may be more efficient while in others it may not (e.g. good at algebra but not geometry). Also the teaching conditions are not always ideal. The mathematician must be ready at all times to be able to adapt what he has designed to teach, so as to meet the learning needs and requirements of each student.

5) The teacher should not be authoritarian and absolute, but neither should he be lax. Students should always be given time for dialogue and if he deviates from the lesson, then the teacher should intervene to bring the students back.

6) The teacher is a tireless regulator and observer of students' progress and this should be seen in the mathematics class, without of course being the protagonist. It is desirable that students play a leading role and not a teacher. After the end of the lesson, the students' impression should be that the knowledge was acquired by them and not that it is provided entirely or in a very large percentage by the teacher.

7) The mathematician, in addition to being a teacher, is also a human being. He has his pros and cons and he is certainly not omniscient. There may be areas he may not be aware of or remember (such as facts from the history of mathematics). It is not bad to tell students that he does not know a subject well and that he will research and answer in the next lesson. Uncertainty in mathematics is neither welcome nor expected, with the consequence that its potential presence may embarrass many teachers, even some of those who would accept it more easily in other subjects [4].

\subsection{Mathematics Classroom Feedback}

In general, feedback is defined as the process of gathering and providing infor- 
mation to the supervisor about the progress of one of his associates and the continuous improvement of both.

In the workplace, productivity feedback is wrongly considered undesirable, because it is subconsciously combined with unpleasant situations such as reprimands, seizures, and possibly layoffs. Getting proper feedback is not the only solution for a person's efforts, but it is also a great way to improve your already good efforts. Also, the right feedback is not a one-way street, that is, it is not always given by a subordinate to his boss, but it also works the other way around. It can even be provided between two colleagues, or two classmates in the same class.

Feedback through performance appraisal obviously has its roots in the production process and methods of improving performance. Because at school the students are evaluated for their performance, the feedback is transferred with several differences in the educational process. Outside of school, it is a stressful process for the existing one, since the work he has done is evaluated, with very formal procedures, in the area of his head, at regular intervals. In education, however, proper assessment works differently. It is continuous, in every second of the lesson, without tiring and causing discomfort, it is a more relaxed process from the teacher to all students and vice versa and with the sole aim of improving the skills and performance of students and way of teaching the teacher.

The feedback can also be done without any special planning between colleagues, not necessarily of the same specialty, in the office space or even in their meetings with the specialty consultant. A nice exercise, a collection of methodologies or questions given by a colleague or even the reference of a pedagogical experience from a teaching class, has a well-intentioned goal of improving the quantitative and qualitative educational process but also the faster treatment of some problems. This should be extremely accepted and thanked, because it is not a critique of the work of other colleagues, but instead contributes to a change for the better.

Feedback in the mathematics classroom is the constant information about the effectiveness of teaching and the performance of students in the mathematics lesson, while providing assistance from the teacher to his/her students, so that they can improve their performance. This help can be provided either in the form of comments or questions, or by note on the student's board or notebook, or even by posture, possibly by the use of nods, gestures and facial expressions of the teacher. The immediate consequence is that feedback in the mathematics class is not just about indicating whether the student's answer is correct or incorrect, but in case of error the approach by the mathematician with available mathematical textbooks and examples and the simulation with real situations as problems, to help the student give the correct answer (and of course to be praised). The questions are asked throughout the teaching and at the end of the teaching, to evaluate the achievement of its objectives [5] [6]. Race argues that feedback should be provided shortly after assessment so that students are still able to remember the details that preoccupied them during their examination. 
Feedback is not static. Feedback is not a four-month grade or a written test, nor a student's awareness of problems and difficulties, but must be accompanied by all necessary steps to remove obstacles to progress and achievement of goals. Correcting mistakes is an effective approach for simple tasks, but for more complex teaching materials learning needs more interactive feedback [7].

The teacher, who does not want to remain stagnant and seeks its continuous improvement, must apply the feedback knowing that it is a two - way process that is provided and received at the same time because according to Dimitropoulos [8], it also concerns the educational work of teachers. The goal of feedback should always be to improve the teacher, increase his/her efficiency, as well as support and motivate him/her to make a greater effort. Feedback is not linked to punishment. After all, it's not just negative. It requires a discussion between teachers and students in a calm tone, with confrontations but not attacks.

\subsection{Why Do Students Need Feedback?}

There are many reasons that make feedback in education very important, whether it is provided by the students or vice versa. Research by Wiliam, Lee, Harrison and Black [9] states that its application increases students' learning by $70 \%$ or otherwise, as if there are an additional 8 months of learning each year! Feedback promotes ongoing reassessment of established teaching methods and learning strategies. As a result, focusing on the process of editing a project promotes in-depth learning, improves performance, and helps develop students' self-awareness, self-esteem, and self-efficacy [10] [11]. Teachers' strong beliefs of their teaching efficacy are of principal importance [12], because they promote students' self-regulation [13] and changing their dysfunctional perceptions and behaviors [14] [15]. This gets more important since recent data shows that teachers believe that they do not receive the adequate support from official institutions [16].

When the mathematician in the classroom gives feedback to the students, then he/she encourages them to mobilize and makes them more confident about the way they are working, so that they get closer to mastering the theory and solving the exercises. Mathematics is slowly ceasing to be just abstract concepts, acquiring structure and substance and creating pleasant emotions when dealing with them. The student feels that he communicates better with his/her teacher and with the positive reinforcement he/she receives, he/she starts and trusts him/her, thus making the task of both simpler and more enjoyable.

Many times students, on their enthusiasm to solve an exercise, either ignore some facts (data of the exercise) or choose the wrong path. The mathematician with the feedback, returns to the right course every student who follows the wrong methodology, something that is very easily observed in mathematics, even by very good students. Students see and review their mistakes and possibly some concepts they have not understood.

The teacher's suggestions for the correct use of symbols and variables, as well as for a correct shape if needed, can help in the thought process. The mathema- 
tician turns a situation into the shortest path to the final solution and the final result, more easily and quickly, showing alternative paths. Using the correct mathematical formula in algebra and geometry, or a finding in geometry can save a lot of time and many tasks to solve an exercise, while minimizing the possibility of error.

With the feedback the morale and the performance of the student rises and this is seen in the written and oral tests, but also in the fact that he/she seeks (needs) less the teacher in the classroom, gaining over time a fairly large percentage of autonomy. He/she can even, if necessary, solve questions of his/her classmates, thus creating a pleasant and constructive atmosphere in the classroom. At the same time, the teacher is given more time to go deeper into the lesson, to read the historical notes that exist in the textbooks and usually go unnoticed and to assign individual or group tasks. Students are also given the opportunity to reflect on issues related to their learning and learning needs [17].

Mathematics becomes the student's property and a necessary resource for him to be able to proceed either to the next class or to the next level of education. Along with the answers that the student gets about the value of mathematics, he/she is given the opportunity to use mathematics outside of school in everyday life or to manage and develop them in any way he wishes in his/her later professional career.

\subsection{How Is Proper Feedback Provided?}

It is widely accepted that the teacher-centered education system is a failed model. His weaknesses are visible to every teacher, from the first second he enters the classroom, to the dissatisfaction of the students throughout the lesson and the feeling of relief when it ends. It is also reflected in the competitions and in the general progress of the students. There are many reasons for the failure of this system, the main ones being the inactive participation of the students but also the total lack of proper feedback. In many cases, traditional forms of feedback have led to a reduction in student achievement [18]. The feedback requires frequent breaks during the lesson, so that the teacher understands if the new concepts are understood by the students and makes the necessary corrections and clarifications. In particular, the fellow mathematician, coming to the mathematics class, must keep in mind the following:

1) According to Rodgers [19] and Brookhart [20] feedback is given by the recognition and confirmation of achievements. Positive comments are mandatory, but it is good to give them sparingly, because in case they do not suffer from some incorrect answer, the student is troubled, passing the doubt inside. But even in the case of a correct answer, there is a risk that the student will be confused, not knowing exactly what he did correctly. On the other hand, in case of a wrong answer from a student, the teacher should react calmly. The error should not be reported, on the contrary the mathematician should make the most of the error to give counter-examples. In any case the teacher must be interested in his students and according to Hopkins [21], when teachers are inter- 
ested in their students, this is evident from all their non-verbal behavior. According to Perrott, non-verbal reinforcement of the student, such as a sincere smile or a look of praise, can be more effective than verbal.

2) Because mathematics is multilevel, the teacher must immediately inform the student in which areas he/she is capable and what he/she can improve and not waste time waiting for the next lessons.

3) The right mathematician is always close to the students, without discriminating. He/she always finds time to talk to them. Above all, however, it sets goals, always in consultation with the students, about what they can achieve. It can even enumerate objects, such as constructing shapes, performing operations or even improving memory by helping to memorize many mathematical formulas and theorems. Over time, after first asking the student about his/her progress, he/she should inform him/her about how much he/she has improved, how close he/she is to the goals and what he/she needs to do to achieve them. Throughout the period, the teacher should have cultivated such a climate, so that the student alone can know at what stage he/she is and how much he/she has improved in relation to his/her initial performance and at which specific points he/she should ask for suggestions for improvement from his/her teacher. Under no circumstances should he/she be compared to his/her classmates [18].

4) A large percentage of the feedback given in the math class comes from their classmates. According to Hattie [22], students provide $80 \%$ of verbal feedback. It is the teacher's responsibility to describe to the students who can find help, but also how they can offer their help to other classmates. It has been observed that one knows something really well when one is able to teach it to someone else. Students know this very well. They will gladly and willingly give their help to a classmate.

5) According to Earl [17] proper feedback gives students time to think and act according to the indications and instructions given to them. It is good for students to have a sense of freedom and not feel that they are being graded, checked and examined at every moment of math class.

6) The feedback in education and especially in the mathematics lesson, is done to push the students to reach higher levels. The teacher should not forget that the feedback is given personally to each student. In the case of group feedback, students are more likely to be indifferent, believing that it is addressed to others. Also, there must be a higher cognitive limit every time and on the teacher's enthusiasm not to exceed it.

7) In any case, he/she must listen to the students, the right and the wrong answers. In case of error he/she must repeat the question in a different wording, without of course making the answer obvious. When the mistake is exploited correctly and the right is reconstructed through the mistake, then the student is not disappointed and is led to learning [23]. It is good to ask additional questions to increase in-depth understanding. With our questions we offer the opportunity to students to identify difficulties and gaps, to understand the mistakes they had and to correct them. 
8) Feedback does not end in the classroom. Homework should not be out of school textbooks, because many students easily find their solutions ready. They also do not have to be printed before the lesson starts. The teacher must have prepared assignments and depending on how the lesson progressed, modify them and give them in the last five minutes. The activities assigned to students should go hand in hand with their spiritual and learning level, increasing their degree of difficulty gradually, in order to avoid disappointments [24]. It is very important to show the students how they can control their work and makes sure that their exercises are few, characteristic and original.

9) It is good to have time for action on the student, limiting the teacher the number of instructions and directions he/she gives to correct. Finally, feedback is used by the mathematician, not to deal with a whole unit, but some elements of theory or some points of an exercise that were not understood.

10) Because the mathematician is a role model for students, he/she must be reliable. The provision he/she will give to students must be valid and the information must be correct.

\section{Research Part}

\subsection{Research Methodology}

In the following research, the quantitative research was selected and the analysis was done through the statistical program SPSS. A collection was made with the help of a questionnaire.

The importance of research lies in the fact that, while many other studies have been conducted on the learning climate for feedback, so far nothing similar has been done for the mathematics class. The research concerns the following research questions:

1) How are students' views on the learning climate in the mathematics classroom shaped?

2) How are students' views on the feedback they receive in math lessons formed?

3) Is there a correlation between students' performance and the learning climate and/or the feedback that students receive in the math class?

The research was carried out on 50 high school students ( 26 boys - 24 girls) of whom 23 are students in the A Lyceum A and 27 in the B Lyceum, in schools of the prefectures of Boeotia and Evia. Adhering to the basic principles of ethics, such as personal data protection, the questionnaire was completed online, answered anonymously by students and the answers will not be used for anything other than the present research. The students also had the opportunity not to answer, without anyone being able to control it. The questionnaire contained two demographic questions related to class and gender and 30 questions divided into two sections of 15 . In the first section, which concerns the learning climate in the mathematics class, students were asked to answer on a 7-point scale (from 1 up to 7 that is), where: 
$1=\mathrm{I}$ completely disagree, $2=\mathrm{I}$ strongly disagree, $3=\mathrm{I}$ disagree a little, $4=$ neutral, 5 I agree a little, $6=\mathrm{I}$ strongly agree and $7=\mathrm{I}$ totally agree.

The average of the answers of the first section ranged around 5, with values from 4.18 to 5.92 and the standard deviation (S.D.) from 1.3 to almost 2.

In the second section, which concerns the feedback in the mathematics class, the students were asked to answer on a scale of 4 points (i.e. from 1 to 4 ), where:

$1=$ never/not at all, $2=$ a little, $3=$ sometimes/enough and $4=$ always.

The average of the answers of the second section ranged around 3 , with values from 2.06 to 3.74 and the standard deviation from 0.44 to 0.62 .

The reliability of the questionnaire was tested with the internal consistency coefficient of Cronbach's alpha which takes values from 0 to 1 . The first section had a coefficient of 0.896 and the second 0.703 , in each case it is greater than the limit of 0.70 .

\subsection{Research Results}

After having the above-mentioned survey conducted, the following results came up as presented Table 1 and Table 2. More specifically after each table is following the analysis of each research question.

See Table 2.

Table 1. Questions about learning climate in the mathematics class.

\begin{tabular}{|c|c|c|}
\hline LEARNING CLIMATE & Average & S.D \\
\hline 1.1 I feel that my teacher offers me options. & 4.88 & 1.39 \\
\hline 1.2 I feel understood by my teacher. & 5.22 & 1.57 \\
\hline 1.3 I am able to be open with my teacher in the classroom. & 4.56 & 1.89 \\
\hline 1.4 The teacher gave me confidence in my ability to continue well. & 5.54 & 1.36 \\
\hline $1.5 \mathrm{I}$ feel that my teacher accepts me. & 5.56 & 1.50 \\
\hline $\begin{array}{l}\text { 1.6 My teacher made sure I understood the goals of my course and } \\
\text { what I should do. }\end{array}$ & 4.98 & 1.80 \\
\hline 1.7 My teacher encouraged me to ask questions. & 5.08 & 1.85 \\
\hline $1.8 \mathrm{I}$ feel very confident in my teacher. & 5.02 & 1.72 \\
\hline 1.9 My teacher answers my questions completely and carefully. & 5.52 & 1.70 \\
\hline 1.10 My teacher listens to how I would like to do things. & 5.00 & 1.85 \\
\hline 1.11 My teacher handles people's emotions very well. & 4.94 & 1.58 \\
\hline 1.12 I feel that my teacher cares about me as a person. & 5.00 & 1.75 \\
\hline 1.13 I do not feel very well about the way my teacher speaks to me. & 2.08 & 1.45 \\
\hline $\begin{array}{l}\text { 1.14 My teacher tries to understand how I think, before I suggest a new way } \\
\text { of doing things. }\end{array}$ & 4.56 & 1.69 \\
\hline $1.15 \mathrm{I}$ feel able to share my feelings with my teacher. & 4.18 & 1.96 \\
\hline
\end{tabular}


Table 2. Questions about feedback in the mathematics class.

\begin{tabular}{|c|c|c|}
\hline FEEDBACK & Average & S.D \\
\hline 2.1 Does the math teacher praise you when you are reading? & 3.10 & 0.45 \\
\hline 2.2 Does the math teacher tell you that you are a good student? & 2.76 & 0.46 \\
\hline 2.3 Does the math teacher think you are smart? & 3.28 & 0.46 \\
\hline 2.4 Do you generally receive praise from your math teacher? & 2.80 & 0.46 \\
\hline 2.5 Does your math teacher treats you well? & 3.74 & 0.56 \\
\hline 2.6 Does the math teacher love you? & 3.16 & 0.45 \\
\hline 2.7 Does the math teacher help you when you have difficulty with theory? & 3.20 & 0.46 \\
\hline $\begin{array}{l}2.8 \text { Does the math teacher help you when you have difficulty with } \\
\text { exercises in some points? }\end{array}$ & 3.48 & 0.50 \\
\hline $\begin{array}{l}2.9 \text { Does the math teacher help you when you have difficulty starting } \\
\text { the solution of an exercise? }\end{array}$ & 3.38 & 0.48 \\
\hline $\begin{array}{l}2.10 \text { When you don't remember the methodology, does the math teacher } \\
\text { help you? }\end{array}$ & 3.16 & 0.45 \\
\hline $\begin{array}{l}2.11 \text { When you make mistakes in the methodology of solving an exercise, } \\
\text { does the math teacher remark on you? }\end{array}$ & 2.58 & 0.49 \\
\hline 2.12 Does the math teacher comment on you in general? & 2.32 & 0.54 \\
\hline $\begin{array}{l}2.13 \text { Does the math teacher remark to you when you are not paying } \\
\text { attention in class? }\end{array}$ & 3.00 & 0.45 \\
\hline 2.14 Does the math teacher give you low grades? & 2.06 & 0.61 \\
\hline 2.15 When you are illiterate, does the math teacher remark on you? & 2.46 & 0.51 \\
\hline
\end{tabular}

\section{Discussion}

\subsection{Discussion about Learning Climate in the Mathematics Class}

Students recognize that the mathematician offers them options but look for more. This follows from the question:

1.1 I feel that my teacher offers me options.

Average: 4.88

Students perceive great understanding and great acceptance by their teacher. This raises the following questions:

\begin{tabular}{lc}
\hline 1.2 I feel understood by my teacher. & Average: 5.22 \\
1.5 I feel that my teacher accepts me. & Average: 5.56 \\
1.6 My teacher made sure I understood the goals of my course and what & Average: 4.98 \\
I should do. &
\end{tabular}

Students are reluctant to express their feelings in the classroom and show great introversion, with the average of the following answers slightly exceeding the base of 4 : 
There is quite a lot of trust on the part of the students in the teacher:

Students recognize that there is great encouragement from the teacher to ask questions and that careful answers are given:

1.7 My teacher encouraged me to ask questions.

Average: $\mathbf{5 . 0 8}$

1.9 My teacher answers my questions completely and carefully.

Average: 5.52

Students notice a slight difficulty of the teacher in his emotional manipulations in the classroom:

1.11 My teacher handles people's emotions very well.

Average: 4.94

\subsection{Discussion about Feedback in the Mathematics Class}

The high average value of the following answers proves that a math teacher often praises his students when they are read, believes that they are smart enough, treats them very well and loves them enough:

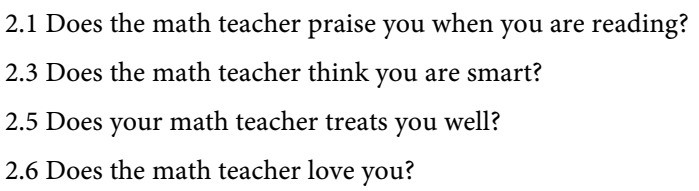

Students, to a very large extent, can count on the help of a math teacher:

2.7 Does the math teacher help you when you have difficulty with theory?

Average: 3.20

2.8 Does the math teacher help you when you have difficulty with exercises in some points?

Average: 3.48

2.9 Does the math teacher help you when you have difficulty starting the solution of an exercise?

2.10 When you don't remember the methodology, does the math teacher help you?

Average: 3.16

The math teacher makes a few remarks, especially to the indifferent students:

2.11 When you make mistakes in the methodology of solving an exercise, does the math teacher remark on you?

2.12 Does the math teacher comment on you in general?

2.13 Does the math teacher remark to you when you are not paying attention in class? 
The math teacher evaluates leniently, since the students' answers are far from the base of 2.5:

2.14 Does the math teacher give you low grades?

Average: 2.06

\section{Conclusions and Suggestions}

Many useful conclusions emerge from the research above. Some of the most important are:

1) The first conclusion is that the students want the teacher to offer them more options, thus showing their love and interest for them. Thus Rubin, \& Justice [25], Harder [26], DeVries [27] and Korhonen [28] confirm that: "the teacher must enable students to choose the subject of their employment, the content of learning, the way and their partners in the learning process". Also, "opportunities for learning in mathematics and the increase in the student's time spent dealing with them have a positive correlation with performance" [29].

2) The difficulty of the mathematics lesson is confirmed once again by the feeling that the students have, that they are not understood by their teacher.

3) Students find it difficult to express their feelings and are quite cautious. At this point, the teacher must intervene and with subtle manipulations unlock any anchorage that the student has. The trainer should be aware of the symptoms of anxiety, fear and anxiety and relieve them in a time [30].

4) Students feel the need for the teacher to be more interested in them and to try to understand how each child thinks and works on it for their progress [1]. He needs the same need to be rewarded for his efforts [31]. This reward is always done mainly for the effort made by the student and not so much for the result of his effort [27].

5) Much of the teaching of mathematics revolves around solving exercises [1]. However, students sometimes feel weak in understanding the theory and therefore feel the need for the teacher to show more patience, to repeat the theory more than once and to give more time to understand the basic concepts. Alcock\& Simpson [32] point out that: "high school students perceive mathematics rather as a problem-solving process".

6) Students want to feel close to the teacher and need feedback. The help offered by the teacher, either in theory or in exercises, is translated and perceived as love and interest [1]. According to Kaattari, [33], a technique in teaching mathematics requires: "monitoring the student's progress at frequent and regular intervals, so that the teaching is fed back and adjusted".

On these conclusions, but also on points that were not sufficiently developed, the possibility for future research and follow-up is given. Some suggestions for further research are:

1) The learning climate and the feedback in a mathematics class that is divided into working groups.

2) The learning climate and the classroom feedback of mathematics with the help of supervisory tools or computers. 
3) Linking the learning climate and feedback in a math class to the curriculum.

4) Greater involvement with theory, methodology and examples, less math exercises.

Of course, in addition to research, every teacher should take care to be constantly updated, to improve his image and to be trained whenever possible. Let us not forget that the final judge is the class itself.

\section{Conflicts of Interest}

The author declares no conflicts of interest regarding the publication of this paper.

\section{References}

[1] Charitaki, G., Tzivinikou, S., Stefanou, G. and Soulis, S.G. (2021) A Meta-Analytic Synthesis of Early Numeracy Interventions for Low-Performing Young Children. SN Social Sciences, 1-38. https://doi.org/10.31234/osf.io/embd7

[2] Pirie, S. and Schwarzenberger, R. (1988) Mathematical Discussion and Mathematical Understanding. Educational Studies in Mathematics, 19, 459-470. http://www.jstor.org/stable/3482272 https://doi.org/10.1007/BF00578694

[3] Cheung, K.C. (1988) Outcomes of Schooling: Mathematics Achievement and Attitudes towards Mathematics Learning in Hong Kong. In: Mathematics Education and Culture, Springer, Dordrecht, 209-219. https://doi.org/10.1007/978-94-017-2209-4 6

[4] Morgan, C. (1998) Writing Mathematically: The Discourse of Investigation. Falmer, London.

[5] Creemers, B.P.M. and Kyriakides, L. (2012) Improving Quality in Education: Dynamic Approaches to School Improvement. Routledge, London. https://doi.org/10.4324/9780203817537

[6] Muijs, D. and Reynolds, D. (2005) Effective Teaching-Introduction and Conclusion. 2nd Edition, Sage Publications, London.

[7] Elshout-Mohr, M. (1994) Feedback in Self-Instruction. European Education, 26, 58-73. https://doi.org/10.2753/EUE1056-4934260258

[8] Dimitropoulos, E. (2004) The Professional Development of the Individual and the Relevant Theories. In: Kassotakis, M., Ed., Counseling and Vocational Guidance: Theory and Practice, Typothito-G. Dardanos, Athens, 101-166.

[9] Black, P., Harrison, C., Lee, C., Marshall, B. and Wiliam, D. (2004) Working inside the Black Box: Assessment for Learning in the Classroom. Phi Delta Kappan, 86, 8-21. https://doi.org/10.1177/003172170408600105

[10] Webb, M. and Jones, J. (2009) Exploring Tensions in Developing Assessment for Learning. Assessment in Education: Principles, Policy and Practice, 16, 165-184. https://doi.org/10.1080/09695940903075925

[11] Hattie, J. and Timperley, H. (2007) The Power of Feedback. Review of Educational Research, 77, 81-112. https://doi.org/10.3102/003465430298487

[12] Antoniou, A.S., Geralexis, I. and Charitaki, G. (2017) Special Educators' Teaching Self-Efficacy Determination: A Quantitative Approach. Psychology, 8, 1642-1656. https://doi.org/10.4236/psych.2017.811108 
[13] Charitaki, G., Soulis, S.G. and Tyropoli, R. (2019) Academic Self-Regulation in Autism Spectrum Disorder: A Principal Components Analysis. International Journal of Disability, Development and Education, 1-18. https://doi.org/10.1080/1034912X.2019.1640353

[14] Thurlings, M., Vermeulen, M., Bastiaens, T. and Stijnen, S.(2012) Understanding Feedback: A Learning Theory Perspective. Educational Research Review, 9, 1-15. https://doi.org/10.1016/j.edurev.2012.11.004

[15] Schelfhout, W., Dochy, F. and Janssens, S. (2004) The Use of Self, Peer and Teacher Assessment as a Feedback System in a Learning Environment Aimed at Fostering Skills of Cooperation in an Entrepreneurial Context. Assessment and Evaluation in Higher Education, 29, 177-201. https://doi.org/10.1080/0260293042000188465

[16] Tzivinikou, S., Charitaki, G. and Kagkara, D. (2020) Distance Education Attitudes (DEAS) during Covid-19 Crisis: Factor Structure, Reliability and Construct Validity of the Brief DEA Scale in Greek-Speaking SEND Teachers. Technology, Knowledge and Learning, 1-19. https://doi.org/10.1007/s10758-020-09483-1

[17] Earl, L. (2003) Assessment as Learning: Using Classroom Assessment to Maximize Student Learning. Corwin, Thousand Oaks.

[18] Clarke, A.E. (2005) Situational Analysis: Grounded Theory after the Postmodern Turn. Sage, Thousand Oaks.

[19] Rodgers, B.-L. (2000) Concept Analysis. An Evolutionary View. In: Rodgers, B.L. and Knafl, K.A., Eds., Concept Development in Nursing. Foundation Techniques, and Applications, 2nd Edition, W-B Saunders Company, Philadelphia, Chapter 6, 77-102.

[20] Brookhart, S.M., Walsh, J.M. and Zientarski, W. (2006) The Dynamics of Motivation and Effort for Classroom Assessments in Middle School Science and Social Studies. Applied Measurement in Education, 19, 151-184.

https://doi.org/10.1207/s15324818ame1902 5

[21] Hopkins, C. (1974) Electric Communication: Functions in the Social Behavior of Eigenmanniavirescens. Behaviour, 50, 270-305. https://doi.org/10.1163/156853974X00499

[22] Hattie, J.A.C. (2009) Visible Learning: A Synthesis of 800+ Meta-Analyses on Achievement. Routledge, London.

[23] Katsikas, Ch., Therianos, K., Tsirigotis, Th. And Kavvadias, G.(2007) Evaluation in Education. AA Lebanis, Athens.

[24] Brophy, J. (1986) Teacher Influences on Student Achievement. American Psychologist, 41, 1069-1077.https://doi.org/10.1037/0003-066X.41.10.1069

[25] Rubin, B.C. and Justice, B. (2005) Preparing Social Studies Teachers to Be Just and Democratic: Problems and Possibilities. In: Michelli, N.M. and Keiser, D.L., Eds., Teacher Education for Democracy and Social Justice, Routledge, New York, 79-103.

[26] Corston, S.H., Dolan, W.B., Vanderwende, L.H. and Braden-Harder, L. (2005) U.S. Patent No. 6, 901, 399. U.S. Patent and Trademark Office, Washington DC.

[27] DeVries, R., Zan, B., Hildebrandt, C., Edmiaston, R. and Sales, C. (2002) Developing Constructivist Early Childhood Curriculum: Practical Principles and Activities. Early Childhood Education Series. Teachers College Press, Williston.

[28] Korhonen, J., Linnanmäki, K. and Aunio, P. (2012) Language and Mathematical Performance: A Comparison of Lower Secondary School Students with Different Level of Mathematical Skills. Scandinavian Journal of Educational Research, 56, 333-344. https://doi.org/10.1080/00313831.2011.599423

[29] Suárez-Pellicioni, M., Núñez-Peña, M.I. and Colomé, A. (2013) Mathematical An- 
xiety Effects on Simple Arithmetic Processing Efficiency: An Event-Related Potential Study. Biological Psychology, 94, 517-526.

https://doi.org/10.1016/j.biopsycho.2013.09.012

[30] Meirovich, G. (2012) Creating a Favorable Emotional Climate in the Classroom. The International Journal of Management Education, 10, 169-177.

https://doi.org/10.1016/j.ijme.2012.06.001

[31] Trilianos, Th. (2013) Teaching Methodology. Diadrasi, Athens.

[32] Alcock, L. and Simpson, A. (2002) Definitions: Dealing with Categories Mathematically. For the Learning of Mathematics, 22, 28-34.

[33] Kaattari, T. (2003) Learning Disabilities Training: A New Approach. Funded by the Ontario. Ministry of Training, Colleges and Universities and the National Literacy Secretariat (HRDC). 